\title{
PERFIL SÓCIO-ECONÔMICO DOS ALUNOS, REPETÊNCIA E EVASÃo NO CURSO DE QUíMICA DA UFMG
}

\author{
Mauro Mendes Braga, Clotilde O. B. de Miranda-Pinto e Zenilda de Lourdes Cardeal
}

Departamento de Química - ICEx - UFMG - CP 702 - 31270-901 - Belo Horizonte - MG

Recebido em 24/6/96; aceito em 7/1/97

\begin{abstract}
STUDENTS' SOCIAL AND ECONOMIC PROFILE, FAILURE AND DROPOUT IN THE CHEMISTRY UNDERGRADUATE COURSE AT UFMG. This paper describes a study about the causes for the dropout of chemistry undergraduate students at UFMG in the nineties. The students' social and economic profile was outlined. It was observed a correlation between family income and academic performance and between failure at the beginning of the course and the dropout, but it seems that family income doesn't affect markedly the dropout. The endogenous and exogenous causes contribute equally for the dropout. The authors suggest that the dropout could be significantly reduced if the endogenous causes such as large classes, inadequate curricula and programmes, poor teaching and the unapproachability on the part of the teachers were faced.
\end{abstract}

Keywords: dropout; failure; students' social and economic profile.

\section{INTRODUÇÃO}

A evasão escolar tem sido tema de diversos estudos no Brasil. O enfoque desses trabalhos, no entanto, centra-se no ensino de primeiro grau, notadamente nas primeiras séries. Em relação ao ensino superior, as informações são escassas, destacando-se, nos últimos anos, o estudo de caso realizado por Paredes ${ }^{1}$, em Curitiba. No que se refere ao curso de Química, as publicações mais recentes abordam a situação da UFSCar ${ }^{2}$ e da $\mathrm{UnB}^{3}$. A partir de 1972 , a matéria começou a despertar a preocupação das Universidades Públicas e o interesse do MEC. Em consequência, uma série informações estatísticas foram divulgadas ${ }^{4-7}$. De acordo com os dados relatados, alguns cursos superiores, nas melhores Universidades do país, registram índices de evasão que superam a $70 \%$.

Um desses cursos é geralmente o de Química. No caso da UFMG, no final dos anos 80, a evasão desse curso chegou a alcançar a casa dos $80 \%$. Deve ser ressaltado que a qualidade dos registros acadêmicos da década passada na UFMG recomenda cautela na leitura dessa informação. Por outro lado, índices de evasão preocupantes, nas áreas de ciências e matemática, foram também observados em conceituadas universidades Americanas ${ }^{8,9}$. Entretanto, esse número é bastante elevado para justificar um estudo mais apurado, objetivando conhecer as causas determinantes da evasão, passo primeiro para que se possam desenvolver ações que minimizem o problema.

O presente trabalho procurou correlacionar a evasão do curso de Química da UFMG com o perfil sócio-econômico e o desempenho acadêmico do aluno na Universidade. Os resultados encontrados desautorizam as interpretações simplistas habituais de que a evasão é devida basicamente ao despreparo e/ ou desinteresse do estudante. Ainda que esses fatores possam ser responsáveis por uma parte da evasão, as informações disponíveis parecem indicar que a parcela de culpa da Universidade é pelo menos igual àquela que normalmente se atribui ao ensino secundário ou ao mercado de trabalho.

\section{METODOLOGIA}

O estudo centrou-se nas turmas que ingressaram via vestibular no período 90/95. As informações referentes ao perfil sócio-econômico englobam todo o período; os dados referentes ao desempenho dos alunos referem-se as turmas de 1990 a 1994. Foram dois os fatores determinantes para essa escolha: a confiabilidade dos registros acadêmicos desse período e a possibilidade de se estender, com maior segurança, os resultados do trabalho para os estudantes que irão ingressar na Universidade nos próximos anos. A evasão da década de 80 foi utilizada apenas para efeito de comparação.

Essa escolha acarretou também uma dificuldade que teve que ser contornada. Como o prazo de integralização curricular é de $6,5^{*}$ anos, a evasão final de todas as turmas objeto do estudo teve que ser projetada. Portanto, ainda não se completou a geração de qualquer dessas turmas. No entanto, observou-se, na década de 80 , que a evasão cessava 4 anos após o ano de ingresso da turma. Ou seja, concluiram o curso todos os estudantes que, decorrido esse tempo, não se evadiram. Essa mesma característica foi verificada nas turmas de 90 e 91 , uma vez que os estudantes remanescentes no curso são conhecidos e é razoavelmente seguro prever-se se irão ou não se graduar.

A evasão final das turmas de 92 a 94 foi projetada considerando o tempo médio de permanência no curso dos estudantes ingressantes nos anos anteriores a 92. Por exemplo, a turma de 92, cuja permanência no curso, no momento da análise era de 4 anos, apresentou evasão efetiva de $56 \%$. Mas para as turmas anteriores, a evasão para um tempo de permanência de 4 anos, foi, em média, de $85 \%$ da evasão total da turma. Logo, a evasão estimada para a turma de 92 foi de $66 \%$. Para o cálculo da evasão projetada, esse valor sofreu uma correção adicional, que será descrita mais adiante.

A evasão se caracteriza quando o estudante deixa o curso antes de se graduar. Para efeito desse trabalho, a evasão foi classificada em reopção, transferência e desistência. A reopção ocorre quando, por procedimentos internos à UFMG, que não demandam novo vestibular, o estudante muda de curso. A transferência verifica-se quando o estudante transfere o seu vínculo com o curso de Química da UFMG para o curso de Química de outra Instituição de ensino superior. Qualquer outro motivo que tenha ocasionado a evasão foi classificado como desistência, inclusive os casos em que o aluno foi desligado da Universidade, por baixo rendimento acadêmico ou infreqüência.

Um fator de correção adicional foi introduzido no cálculo

\footnotetext{
Por prazo de integralização curricular entende-se o tempo máximo que o estudante pode permanecer no curso. No caso do curso de Química da UFMG, o currículo padrão está organizado para permitir a formatura em quatro anos.
} 
da evasão. A UFMG tem por norma ofertar as vagas geradas por evasão para admitir estudantes via transferência, obtenção de novo título ou mesmo a readmissão de alunos excluídos, procedimento denominado de rematrícula. Uma parcela, ainda que pequena, dos alunos ingressantes através dessas formas se gradua e reduz a evasão. Esse fator foi estimado verificando-se, ao longo de uma década, o percentual dos formandos que ingressaram via vestibular. Observou-se que ele reduz a evasão em cerca de $6 \%$, proporção que foi aplicada a todas as turmas. A evasão foi, portanto, calculada usando o conceito de evasão estimada anteriorente referido e a seguinte expressão:

$\%$ Evasão $=100 \%$ - \% Formandos - 0,06 (100\% - \% Formandos), sendo que \% Formandos indica a percentagem de estudantes da turma que deverão se graduar, calculada de acordo com a expressão:

$\%$ Formandos $=100 \%$ - \% Evasão Estimada.

Como exemplo, aplicando a fórmula acima para a turma de 92, ter-se-ia:

$\%$ de evasão já efetivada $=56 \%$;

$\%$ de evasão estimada $=66 \%$

$\%$ de formandos $=34 \%$

$\%$ de evasão $=100 \%-34 \%-0,06 \times 66 \%=62 \%$

Deve ser ressaltado que, nos estudos de evasão divulgados, nem sempre adotou-se a sistemática de acompanhar cada turma. Às vezes, escolheu-se algum tipo de procedimento que focaliza sua atenção no fluxo de alunos, confrontando o número de formandos com o de ingressantes e com o tempo de integralização curricular1,5. Em outros $\operatorname{casos}^{7}$, não foram incluídos fatores de correção essenciais, tendo em vista o processo de ocupação das vagas geradas pela evasão. Os autores acreditam que a metodologia por eles empregada, acompanhando cada turma e a eventual ocupação das vagas geradas, descreve melhor o fenômeno estudado.

O perfil sócio-econômico dos estudantes foi traçado a partir de questionário preenchido pelos candidatos ao concurso Vestibular. A esses dados foram acrescentadas algumas informações constantes do registro acadêmico.

O rendimento acadêmico dos estudantes no curso foi determinado considerando-se apenas a aprovação ou a reprovação nas quatro disciplinas do primeiro período da grade curricular, a saber: Cálculo, Geometria Analítica, Química Geral e Programação de Computadores. As duas primeiras são ministradas pelo Departamento de Matemática, a terceira, pelo Departamento de Química e a última, pelo Departamento de Computação, todos eles integrantes do Instituto de Ciências Exatas (ICEx). Os trancamentos de matrícula, parcial ou total, foram considerados como reprovação; as eventuais dispensas de disciplinas, como aprovação. Essa escolha se justifica pelas razões expostas a seguir.

A tentativa de expressar o rendimento acadêmico dos estudantes considerando toda a sua trajetória no curso apresentaria grandes dificuldades, dentre as quais se destacam: a definição de uma fórmula que possibilitasse expressar numericamente esse desempenho; o sistema de matrícula por disciplina adotado pela UFMG permitir, a partir do segundo período do curso, que os alunos se matriculem em disciplinas diferentes, dificultando um estudo comparativo, caso todas as disciplinas sejam consideradas; o fato de as quatro disciplinas iniciais do curso não terem sofrido modificação de conteúdo, carga horária ou ementa, no período considerado, o mesmo não podendo se dizer para todas as demais disciplinas da grade curricular; a possibilidade de se comparar estudantes de turmas diferentes e o tempo que seria consumido na coleta dos dados.

Ademais, o primeiro período do curso é exatamente aquele que exerce maior impacto sobre o estudante na Universidade. As dificuldades de adaptação são naturalmente maiores, sobretudo na área de Ciências Exatas na qual as disciplinas do departamento de Matemática geralmente representam um obstáculo de expressivo significado. Portanto, o sucesso do aluno no primeiro período permitiria concluir, com razoável dose de segurança, que esse estudante teria formação secundária adequada para o curso escolhido. Finalmente, deve ser registrado que verificou-se uma relação linear entre evasão e repetência no primeiro semestre curricular.

A UFMG oferece curso de Química nos turnos diurno e noturno. O curso noturno, no entanto, iniciou-se recentemente, em 1994. Portanto, o presente estudo limitou-se a considerar o curso diurno.

Os resultados encontrados nesse trabalho foram apresentados, em um seminário, para os estudantes - graduação e pósgraduação - e professores do Departamento de Química. Após a exposição, os presentes tiveram oportunidade de se manifestar sobre o tema, sendo numerosas e demoradas as intervenções. As impressões colhidas nessa oportunidade, ainda que às vezes antagônicas e obtidas sem qualquer critério estatístico, serão eventualmente incorporadas à discussão apresentada nesse texto.

\section{RESULTADOS E DISCUSSÃO}

A figura 1 apresenta a evasão registrada pela PROGRAD no curso de Química da UFMG, se o cálculo for efetuado conforme descrito anteriormente. A despeito de algumas oscilações observadas, sobretudo no ano de 1987, duas conclusões podem ser inferidas: a evasão apresentou tendência de crescimento ao longo da década passada e os índices alcançados ao final desse período foram insuportáveis. Diante desses fatos, no início dos anos 90, o Colegiado de Curso procurou atuar no sentido de minimizar o problema. A ação se concentrou na organização do fluxo curricular e em melhorar o processo de acompanhamento e orientação dos estudantes.

A estratégia do colegiado resultou, de fato, em uma diminuição dos índices de evasão, mas seu efeito foi limitado, uma vez que os percentuais de abandono tendem a se estabilizar em um patamar bastante elevado -em torno de $60 \%$ - como pode ser verificado na figura 2 . Registre-se que a estimativa para a turma de 1994 é menos confiável, uma vez que essa turma ingressou na Universidade mais recentemente.

Ainda que esse patamar seja inferior aos níveis de evasão observados na UnB e UFPR e da mesma ordem de grandeza que os percentuais registrados na PUC-PR e na UFSCar, índices de evasão dessa magnitude indicam a existência de graves problemas.

A evasão é ocasionada fundamentalmente pela desistência, conforme pode ser verificado na figura 3 , razão pela qual o estudo realizado priorizou esse evento. Ademais, a reopção, que foi uma ocorrência de frequiência considerável até meados da década passada, registra índices francamente declinantes nos anos 90 .

Para compreender um pouco melhor o fenômeno da evasão, analisou-se o perfil sócio-ecônomico do estudante de Química. Em alguns poucos aspectos, o calouro de Química apresenta características similares às dos alunos ingressantes na UFMG: são solteiros, com idade média de 20 anos, concluíram o $2^{\circ}$ grau em Belo Horizonte, sendo que cerca de $60 \%$ deles têm até 19 anos; aproximadamente $85 \%$ cursaram a escola secundária no turno diurno; da ordem de $37 \%$ deles obtiveram sucesso no primeiro vestibular que fizeram na UFMG e o mesmo percentual logrou êxito na segunda tentativa. Em ambos os casos são, portanto, estudantes jovens e regulares.

As semelhanças terminam por aí. Nos demais quesitos considerados, há expressiva diferença entre o perfil sócio-econômico dos dois grupos de estudantes pesquisados. No que se refere à formação secundária, por exemplo, $62 \%$ dos calouros da UFMG são oriundos de escolas privadas, enquanto apenas $37 \%$ dos alunos ingressantes no curso de Química vêm de escolas particulares. Ademais, no caso da UFMG, esse percentual permanece 


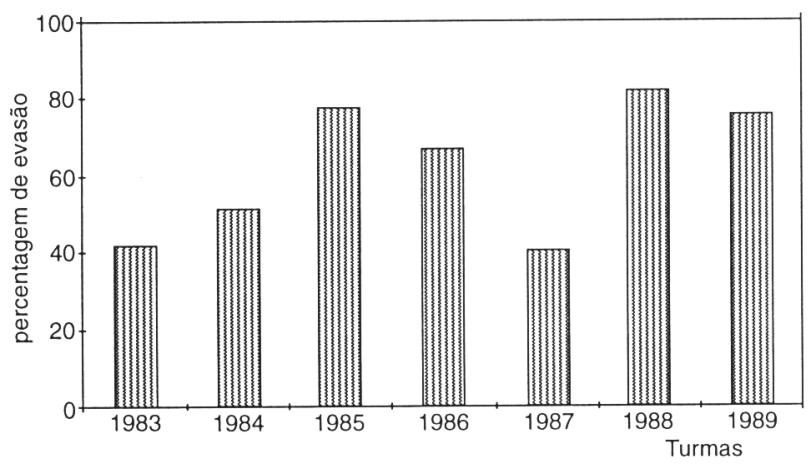

Figura 1. Evasão no curso de Química da UFMG na década de 80.

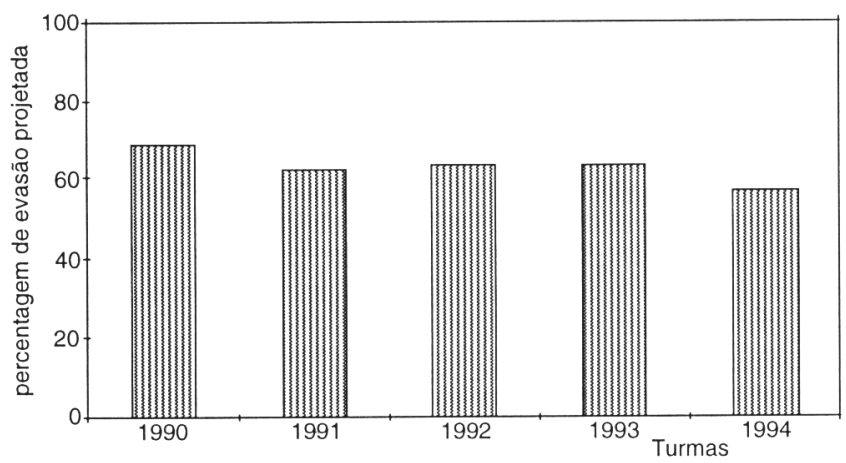

Figura 2. Evasão projetada para a década de 90 no curso de Química da UFMG.

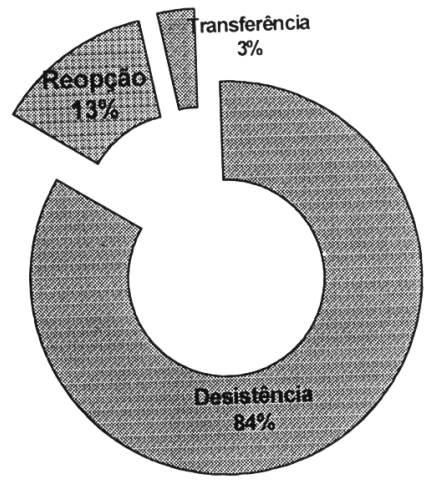

Figura 3. Perfil da evasão no curso de Química da UFMG na década de 90.

praticamente invariável desde 1991, mas, no curso de Química, a proporção de alunos vindos do sistema público aumentou continuamente a partir daquele ano, como pode ser observado na figura 4. É também expressivo o contigente de calouros de Química com formação secundária profissionalizante (ver figura 4) - 53\% na média dos 6 anos considerados - ainda que a partir de 92 esse percentual venha diminuindo. Do total de estudantes de Química oriundos de cursos profissionalizantes, quase $80 \%$

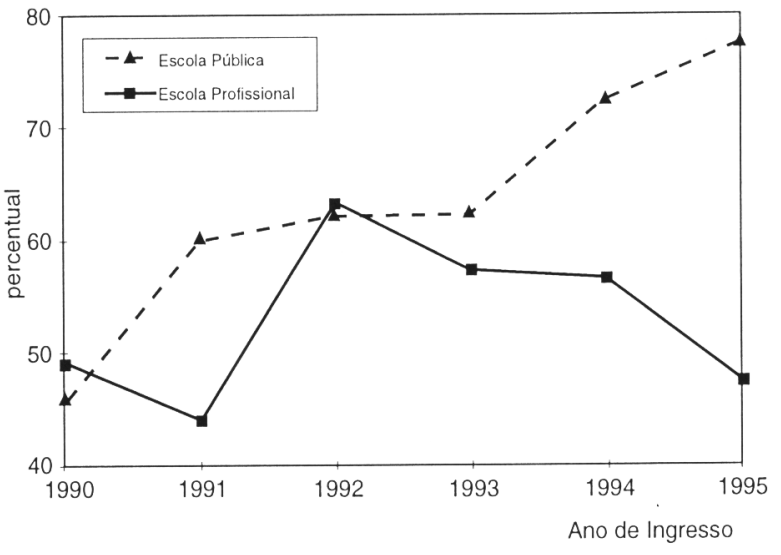

Figura 4. Formação secundária dos estudantes de Química.

concluíram o curso secundário em duas escolas técnicas federais de ótima reputação: o Centro de Educação Tecnológica de Minas Gerais (CEFET) e o Colégio Técnico da UFMG (COLTEC). Já no caso da UFMG, a proporção de estudantes vindos de cursos profissionalizantes é bem menor, $25 \%$, tendo sofrido alterações pouco significativas no período relatado.

A tabela 1 apresenta alguns dados realçando as diferenças entre o perfil sócio-econômico dos calouros de Química e da UFMG. Torna-se evidente que o aluno de Química é oriundo das camadas menos favorecidas da classe média.

A renda familiar média do estudante de Química, que havia crescido de 13,4 para 15,4 salários mínimos (SM), de 1990 para 1991, declinou consideravelmente no período 91/94, atingindo valores inferiores a 8,0 SM. Em 1995 houve uma expressiva reversão dessa tendência e o valor verificado foi de 12,6 SM. Cotejando esses resultados com a figura 2, conclui-se não haver correlação entre renda familiar média e evasão. O mesmo pode ser dito com referência aos demais indicadores constantes da tabela 1 .

A desistência (e, portanto, a evasão) não ocorre homogeneamente nos diferentes subgrupos de alunos que podem ser formados entre os estudantes de Química, como pode ser verificado na tabela 2. Em geral, os grupos formados por estudantes do sexo feminino e por alunos oriundos de escola pública registram desistência bem inferior à média global. A formação secundária do aluno, se profissionalizante ou não, parece não afetar de forma significativa a evasão. No entanto, quando se combina curso profissionalizante com escola pública e estudante do sexo feminino, resulta uma desistência bem inferior à média global.

A figura 5 ilustra o rendimento acadêmico dos calouros de Química no período considerado, em termos de aprovação e reprovação nas disciplinas do primeiro semestre curricular. Como se vê, quase metade dos alunos logram aprovação nas quatro disciplinas cursadas. No caso do ICEX, unidade à qual se vincula o curso em estudo, é razoável considerar que estudantes com apenas uma reprovação no primeiro semestre curricular são estudantes de bom desempenho. Dessa forma, quase $60 \%$ dos calouros de Química revelam ter uma formação secundária adequada para as necessidades do curso. Deve ser

Tabela 1. Alguns dados sobre o perfil sócio-econômico dos calouros de química e da UFMG nas turmas de 1990 a 1995.

\begin{tabular}{cccccc}
\hline Curso & $\begin{array}{c}\text { Renda } \\
\text { familiar média }\end{array}$ & $\begin{array}{c}\text { Renda familiar } \\
\text { até } 10 \mathrm{SM}^{*}\end{array}$ & $\begin{array}{c}\text { Renda } \\
\text { familiar maior } \\
\text { que 20 SM }\end{array}$ & $\begin{array}{c}\text { Pais com } \\
\text { instrução } \\
\text { primária }\end{array}$ & $\begin{array}{c}\text { Pai com } \\
\text { instrução } \\
\text { superior }\end{array}$ \\
\hline UFMG & $17,7 \mathrm{SM}$ & $43 \%$ & $29 \%$ & $34 \%$ & $45 \%$ \\
QUÍMICA & $11,5 \mathrm{SM}$ & $64 \%$ & $13 \%$ & $54 \%$ & $25 \%$ \\
\hline
\end{tabular}

* Salário Mínimo 
Tabela 2. Desistência por grupos de alunos.

\begin{tabular}{lc}
\hline Agrupamento & Desistência* $\%^{*}$ \\
\hline Universo & 43 \\
Sexo Feminino & 31 \\
Sexo Masculino & 56 \\
Escola Pública & 40 \\
Escola Particular & 45 \\
Curso Profissionalizante & 43 \\
Curso Colegial & 43 \\
Pública e Colegial & 39 \\
Particular e Colegial & 45 \\
Pública e Técnica & 39 \\
Particular e Técnica & 53 \\
Masculino, Pública e Profissionalizante & 54 \\
Feminino, Pública e Profissionalizante & 29 \\
Masculino, Pública e Colegial & 41 \\
Feminino, Pública e Colegial & 35 \\
Masculino, Particular e Colegial & 52 \\
Feminino, Particular e Colegial & 35
\end{tabular}

*Desistência efetivamente ocorrida até Fevereiro/96; turmas de 90 a 94.

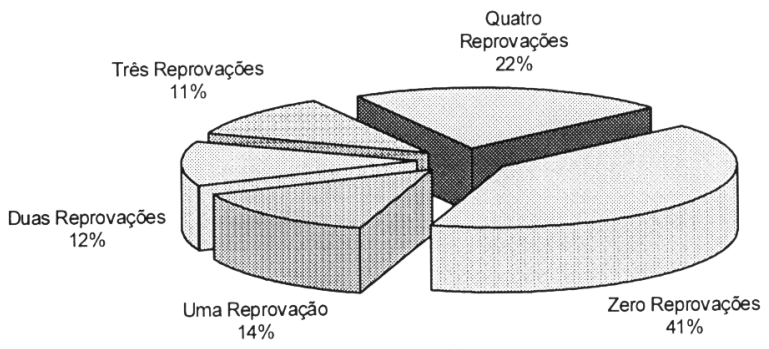

Figura 5. Quantidade de reprovações no primeiro semestre do curso; percentuais médios no período considerado.

também ressaltado que um contigente apreciável dos estudantes encontram dificuldades para aprovação nas disciplinas iniciais: $22 \%$ dos alunos não conseguem aprovação em qualquer das 4 disciplinas, enquanto quase metade são reprovados em mais de uma disciplina. Esse perfil de desempenho não mostra variações significativas com o ano de ingresso, exceto para os alunos de 1990, cujo desempenho acadêmico foi sensivelmente inferior ao observado nas outras turmas.

Conquanto pareça não haver correlação entre evasão e renda familiar, essa última influencia significativamente o desempenho no primeiro período do curso, excetuada a turma de 1990. Para o período $91 / 94$, se o percentual de estudantes sem reprovações for cotejado com a renda familiar média ou com a proporção de alunos oriundos de famílias com renda superior a 20 SM, os coeficientes de correlação linear observados são, respectivamente, 0,93 e 0,95 .

O nível de instrução dos pais parece não afetar significativamente tanto a evasão quanto o desempenho acadêmico da turma. No entanto, deve ser considerado que os autores tiveram acesso apenas a dados globalizados, em relação ao perfil sócio-econômico dos estudantes. Não foi, portanto, possível associar a cada estudante individualmente o grau de escolaridade dos pais, o que poderia resultar em conclusão um pouco diferente da aqui exposta.

Da mesma forma que a evasão, o número de reprovações é bem menor em grupos específicos de alunos. Estudantes do sexo feminino, oriundos de escola pública e com formação secundária profissionalizante apresentam rendimento nitidamente melhor que a média, como pode ser observado na tabela 3 . Quando essas três características estão presentes em um mesmo aluno, geralmente o seu rendimento é excepcionalmente melhor que a média.

O melhor desempenho e/ou a menor evasão associados aos estudantes originários de escolas públicas, ou de escolas profissionalizantes, talvez possa ser atribuído à parcela significativa de alunos que estudaram no COLTEC e no CEFET e à qualidade do ensino ministrado por essas instituições. Não foi encontrada até aqui qualquer explicação plausível para a melhor performance das estudantes, fato que pode inclusive ser considerado surpreendente, uma vez que, até alguns anos atrás, a Química era uma profissão predominatemente masculina.

Como seria de se esperar, a repetência é mais expressiva entre os desistentes, conforme pode ser observado na tabela 3 e comparando-se as figuras 5 e 6 . Mais uma vez verifica-se uma certa correspondência entre evasão e repetência, que será discutida em detalhe mais adiante. No entanto, o número de reprovações não é o único fator que contribui para a evasão. Mais de um terço dos desistentes são alunos de bom desempenho acadêmico no primeiro período do curso.

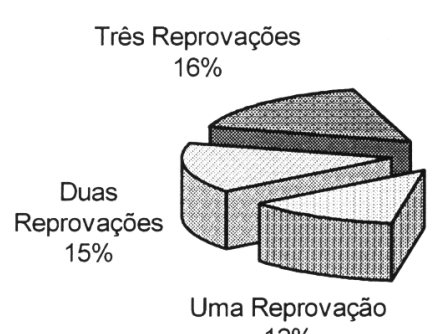

$12 \%$

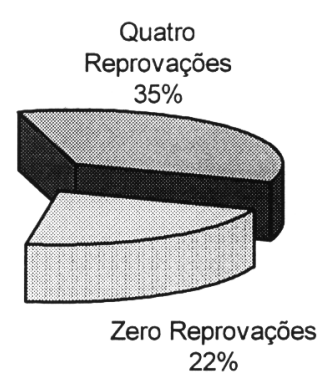

Figura 6. Reprovações dos desistentes no primeiro semestre; percentuais médios no período considerado.

Quais são os fatores determinantes para a evasão não vinculada à repetência? Essa é, certamente, uma pergunta difícil de responder. Habitualmente, ela é justificada pelo desinteresse do aluno pelo curso, originada por fatores externos à Universidade (mercado de trabalho pouco atraente, tanto em número de oportunidades quanto em perspectivas salariais). Essa interpretação merece sérios reparos, ainda que não se desconheçam as crescentes dificuldades que os jovens egressos de cursos superiores, na grande maioria das carreiras, têm para encontrar seu espaço no mercado de trabalho.

Em primeiro lugar, deve ser registrado que o mercado de trabalho para o químico, hoje, é no mínimo tão atraente (talvez fosse mais conveniente dizer tão pouco atraente) quanto o de outros profissionais correlatos, por exemplo engenheiros quími$\cos$ e metalurgistas e farmacêuticos, carreiras para as quais a evasão na UFMG é significativamente menor. O mesmo ocorre em relação aos cursos de licenciatura de outras áreas, como Ciências Biológicas e História. Cabe ressaltar que o mercado no ensino secundário, na região próxima de Belo Horizonte, provavelmente apresente maiores oportunidades para professores de

Tabela 3. Número médio de reprovações no primeiro semestre.

\begin{tabular}{|c|c|c|c|c|c|c|c|c|c|}
\hline \multicolumn{3}{|c|}{ Universo } & \multicolumn{2}{|c|}{ Sexo } & \multicolumn{2}{|c|}{ Escola } & \multicolumn{2}{|c|}{ Curso } & \multirow[b]{2}{*}{ Fem $+\underset{0,89}{\text { publ. }}+$ tec. } \\
\hline $\begin{array}{c}\mathrm{A} \\
1,64\end{array}$ & $\begin{array}{c}\mathrm{B} \\
1,20\end{array}$ & $\begin{array}{c}\mathrm{C} \\
2,28\end{array}$ & $\begin{array}{c}\text { Masc. } \\
1,78\end{array}$ & $\begin{array}{c}\text { Fem. } \\
1,48\end{array}$ & $\begin{array}{c}\text { Pública } \\
1,45\end{array}$ & $\begin{array}{c}\text { Privada } \\
1,93^{`}\end{array}$ & $\begin{array}{c}\text { Colégio } \\
1,87\end{array}$ & $\begin{array}{c}\text { Técnico } \\
1,28\end{array}$ & \\
\hline
\end{tabular}

$\mathrm{A}=$ ingressantes; $\mathrm{B}=$ não desistentes; $\mathrm{C}=$ desistentes 
química que para professores de biologia ou história, considerando o número de diplomados em cada uma dessas áreas. Ademais, o número de oportunidades no magistério de $2^{\circ}$ grau é crescente, fato que tem originado a procura do curso de licenciatura em Química por profissionais já graduados em áreas correlatas.

Por outro lado, o tempo de permanência dos desistentes no curso, apresentado na figura 7 , indica persistência do alunado, sobretudo no caso dos desistentes com bom rendimento no primeiro período do curso, cujo tempo de permanência médio quase chega a três anos ( $\mathrm{O}$ tempo médio de permanência dos desistentes é de 2,9 anos para aqueles com até uma reprovação no primeiro período e de 2,5 anos para aqueles com mais de uma reprovação). Mais da metade dos desistentes permanecem no curso por pelo menos três anos; essa fração supera os $60 \%$, no caso dos desistentes com até uma reprovação. Esses números parecem indicar que o desinteresse de boa parte dos desistentes foi cultivado durante o período em que permaneceu na Universidade. Portanto, nesses casos, talvez seja mais apropriado falar em desilusão que em desinteresse.

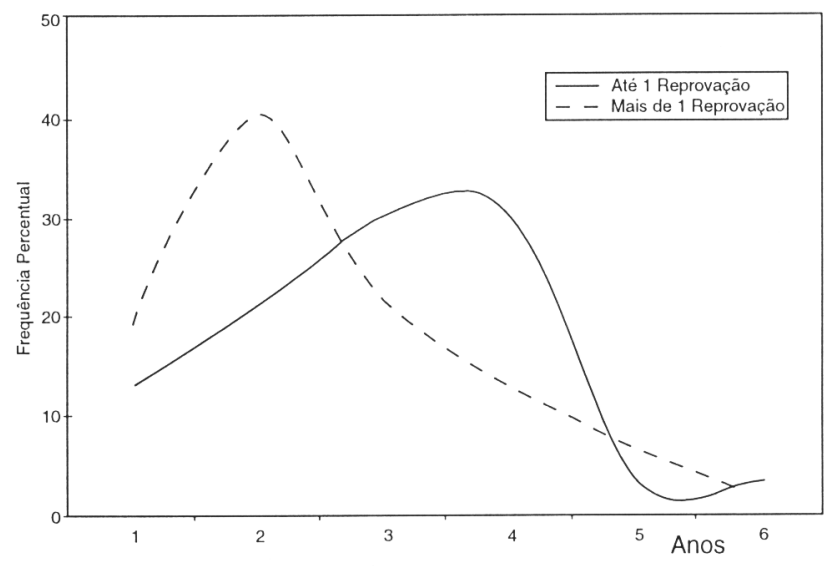

Figura 7. Tempo de permanência dos desistentes em relação ao desempenho no primeiro período do curso.

A visão que os estudantes de graduação apresentam para o problema - evasão de seus colegas de bom rendimento - parece um pouco mais consistente e plausível, ainda que os autores não a adotem integralmente. Essa visão foi apresentada no seminário anteriormente mencionado nesse trabalho e está resumida no texto a seguir. O curso de Química é bastante "puxado", com cerca de 30 horas de aula semanais durante 8 semestres; os professores via de regra são exigentes e nem sempre se esmeram na preparação de suas aulas e na atenção aos alunos; a carga horária referente aos conteúdos de matemática é excessiva - cerca de $15 \%$ da grade curricular - e, juntamente com os conteúdos de física se concentra nos períodos iniciais do curso; consequentemente o calouro quase não estuda química nos dois primeiros semestres do curso.

Esse enfoque mereceu o apoio de parte dos professores presentes ao seminário, mas existiram também muitas vozes - tanto de docentes como de estudantes de pós-graduação - que se manifestaram a favor da expressiva presença de conteúdos de matemática na grade curricular. Por outro lado, muitos professores também reagiram às críticas relativas ao preparo das aulas e à atenção dedicada aos estudantes.

$\mathrm{Na}$ realidade, conhecer os reais fatores que determinam a evasão dos estudantes que apresentam bom desempenho acadêmico requer uma pesquisa de campo. Dessa forma, os próprios sujeitos do evento poderiam explicar as razões que os levaram a deixar o curso. Esse trabalho está em gestação e deverá ser realizado durante o ano de 1996.
Com as informações disponíveis no momento, é mais interessante considerar os fatores que contribuem para a repetência e, em consequiência, para a evasão. A figura 8 demonstra que a repetência no primeiro período do curso é um dos fatores que determinam a evasão. O coeficiente de correlação linear entre o número de reprovações no primeiro período do curso e o percentual de evasão é de 0,995 .

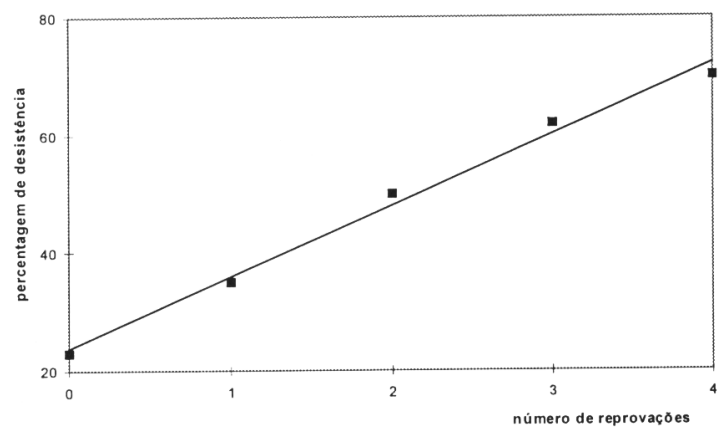

Figura 8. Desistência versus repetência no primeiro período.

As reprovações entre os desistentes ocorrem com maior freqüência nas disciplinas do Departamento de Matemática, conforme mostrado na figura 9, fato que se torna mais evidente quando se exclui o grupo de alunos reprovados em todas as disciplinas, que representa cerca de $35 \%$ dos desistentes.

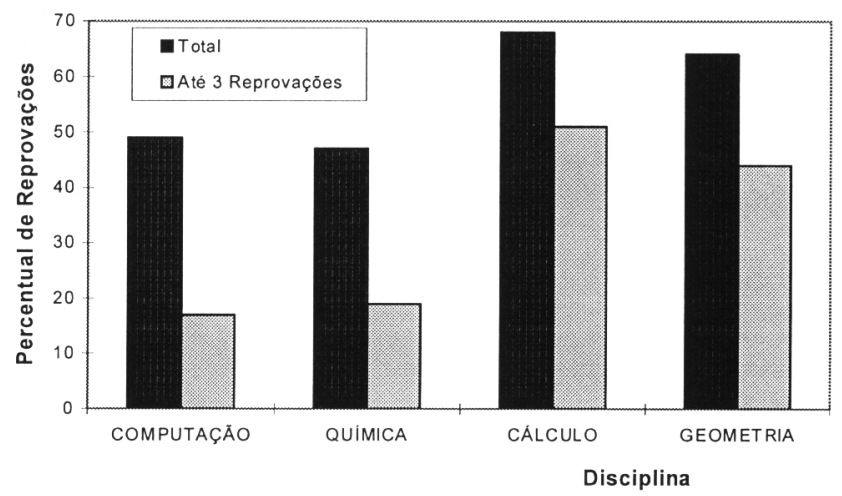

Figura 9. Percentual de reprovação dos estudantes desistentes, por disciplina

Deve ser ainda mencionado que $60 \%$ dos desistentes são reprovados simultaneamente em Cálculo e Geometria, enquanto em Química e Computação a proporção de reprovação concomitante dos desistentes é de $35 \%$. Caso sejam considerados apenas os desistentes com mais de uma reprovação, observa-se que $87 \%$ são reprovados simultaneamente em Cálculo e Geometria, enquanto uma proporção bem menor, 50\%, registra, ao mesmo tempo, insucesso em Química e Computação. Essa diferença entre os dois grupos torna-se mais expressiva quando são considerados apenas os calouros com duas ou três reprovações, que representam $30 \%$ do total dos desistentes: $82 \%$ de insucesso simultâneo em Cálculo e Geometria, contra $3 \%$ em Química e Computação. Torna-se evidente que as reprovações associadas às disciplinas do Departamento de Matemática contribuem decisivamente para os elevados índices de evasão.

O propósito dos autores foi o de verificar como o desempenho no primeiro período do curso influencia o fenômeno da evasão. Por esse motivo fica prejudicada a análise do desempenho dos estudantes na disciplina de Física Geral I, uma vez que, na UFMG, essa disciplina não integra o primeiro semestre 
curricular. Ademais, ela tem como pré-requisito a disciplina de Cálculo I. Dessa forma, muitos dos desistentes sequer chegam a cursá-la, porque não são aprovados em Cálculo. Apenas para registro da informação, que não será aqui discutida, deve ser mencionado que, dentre os desistentes, $30 \%$ não chegam a se matricular em Física Geral, enquanto que dos $70 \%$ que a frequentam, apenas $36 \%$ são aprovados na primeira vez em que nela se matriculam. Isso significa um número médio de reprovações por aluno desistente de 0,63 , na primeira matrícula, ou seja, um padrão de desempenho semelhante àquele observado em Cálculo e Geometria, conforme pode ser observado na tabela 4.

Dentre os desistentes, pode-se identificar um subgrupo, numericamente expressivo (quase $50 \%$ dos desistentes), que registra um padrão de desempenho significativamente melhor que o outro. São os estudantes oriundos de escolas secundárias profissionalizantes. Eles apresentam melhor rendimento, em todas as quatro disciplinas do primeiro período letivo, que os desistentes que freqüentaram o curso colegial. No entanto, esse melhor desempenho é pouco significativo nas disciplinas do Departamento de Matemática, se comparado com as demais disciplinas, conforme mostrado na tabela 4.

Que fator poderia explicar um desempenho tão ruim em Cálculo e Geometria, quando comparado com o rendimento nas outras disciplinas, dos desistentes com formação técnica no segundo grau? Registre-se que algo semelhante é também observado quando são considerados todos os estudantes oriundos de escolas profissionalizantes. Os estudantes com formação secundária profissionalizante, na realidade, têm um número de aulas de matemática bem inferior que aquele normalmente ministrado aos alunos dos cursos colegiais. Portanto, mesmo se formando em excelentes escolas, é natural que revelem dificuldades para acompanhar disciplinas cujos programas são propostos para atender a uma clientela que tenha estudado o programa de matemática do curso colegial. É exatamente essa a situação que ocorre no ICEX/UFMG.

Mas o conteúdo programático não é a única dificuldade que o estudante de Química enfrenta ao chegar à Universidade, sobretudo nas disciplinas ministradas pelo Departamento de Matemática. Salas de 50, 60 ou mais alunos, turmas muitas vezes heterogêneas e estratégias de ensino que quase nunca se preocupam com a recuperação das deficiências demonstradas pelos alunos tornam praticamente impossível que sejam reparadas eventuais lacunas que o estudante traga do curso secundário. Com relação à heterogeneidade das turmas, um requinte de insensatez vem ocorrendo nos últimos semestres: misturamse em uma mesma sala calouros de Química e de Ciência da Computação, estudantes com perfil sócio-econômico e história de vida completamente diversos. Nesse contexto, mais surpreendente que o elevado índice de evasão, seja talvez a persistência demonstrada por alguns estudantes em permanecer no curso de Química.

Não se pretende esquecer que parcela expressiva dos estudantes de Química são oriundos de escolas secundárias cuja qualidade de ensino não é considerada como das melhores de Belo Horizonte. Ainda que a performance nas provas do concurso vestibular não seja indicador confiável para o futuro desempenho do aluno na Universidade, deve ser também mencionado que os calouros de Química muitas vezes registram rendimento sofrível no concurso vestibular, sobretudo nas provas de matemática.

Os autores desse trabalho não pretendem negar que grande parte da evasão -talvez cerca de $50 \%$ - seja ocasionada por uma escolha inadequada de carreira, provavelmente motivada pela baixa concorrência do vestibular. No entanto, acredita-se que foram apresentados argumentos suficientes para se concluir que a evasão resulta também de dificuldades internas do curso, que, uma vez corrigidas, muito provavelmente resultarão em expressiva redução de seus índices.

\section{CONCLUSÕES}

A evasão no curso de Química da UFMG tem causas exógenas e endógenas. Uma tentativa de ponderar cada um desses grupos de causas pode ser feita, conforme descrito a seguir. Em primeiro lugar, supondo que todos os desistentes com 4 reprovações no primeiro período do curso são alunos despreparados para seguir a carreira escolhida. Em seguida, considerando que todos os estudantes que reoptaram de curso já haviam tomado essa decisão antes de ingressarem no curso de Química, portanto seriam alunos desinteressados. Esses dois grupos de estudantes, no seu todo, teriam se evadido em razão de causas exógenas. O mesmo se pode dizer das transferências, uma vez que são provocadas por eventos fortuitos que ocorrem na vida do estudante. As demais evasões, considerando o elevado tempo médio de permanência do aluno no curso, estariam preferencialmente correlacionadas aos fatores endógenos. Fazendo essas hipóteses, observamos que a contribuição das causas exógenas e endógenas praticamente se eqüivalem.

Ou seja, em princípio, é possível, por medidas internas à UFMG, reduzir a evasão do curso de Química para cerca de $30 \%$, que é aproximadamente a média observada quando se considera a UFMG como um todo. Quais medidas poderiam contribuir para isso? Em primeiro lugar, receber os estudantes de forma adequada no curso. Isso significa turmas iniciais com um número de estudantes que permita a adoção de estratégias de ensino apropriadas ao grupo de alunos de Química; programas de Cálculo e Geometria Analítica adequados ao currículo de $2^{\circ}$ grau cursado pelo estudante; organização das turmas de forma homogênea, de preferência com turmas específicas para os estudantes de Química; racionalização da confecção do horário de aula, de tal maneira que este passe a atender o interesse do ensino e não a conveniência dos professores e a indicação, para os períodos iniciais, de professores experientes, interessados, dedicados e pacientes, conforme já sugerido por outros autores ${ }^{8,9}$.

Cumprida a etapa acima, é indispensável uma reforma curricular que reduza significativamente a carga horária de horas/aula e incentive a participação do aluno em programas de Iniciação Científica, bem como em atividades similares tipo PET e PAD. Esse incentivo se efetivará, não só pelo aumento do tempo que o aluno poderá dedicar a essas atividades, inclusive com possibilidade de nelas integralizar créditos, mas também por um melhor gerenciamento das bolsas pelo Departamento de Química. A carga horária do curso de Química da UFMG - cerca de 3200 horas/aula - é indiscutivelmente elevada, uma vez que significa uma média de cerca de 27 horas/aula semanais ao longo de 8 semestres. Essa reforma deve também ter duas outras

Tabela 4. Número médio de reprovações no primeiro período do curso, por disciplina.

\begin{tabular}{lcccc}
\hline & Ingressantes & Formação colegial & Desistentes & Formação técnica \\
Química geral & & 0,57 & 0,30 & 0,47 \\
Computação & 0,36 & 0,52 & 0,36 & 0,49 \\
Cálculo I & 0,33 & 0,71 & 0,61 & 0,68 \\
Geometria analítica & 0,49 & 0,65 & 0,59 & 0,64 \\
Total reprovações & 0,46 & 2,45 & 1,85 & 2,28 \\
\hline
\end{tabular}


características: alterar a grade curricular de forma a reduzir os conteúdos de matemática - excessivos quando se compara o currículo da UFMG com os de outras Universidades do país - e, em conseqüência, antecipar a oferta das disciplinas de química.

As medidas sugeridas nos dois últimos parágrafos têm um custo muito baixo para a Instituição. Não se desconhece que políticas desastradas adotadas pelo governo federal desde o final da década passada provocaram uma enxurrada de aposentadorias precoces e resultaram na diminuição do corpo docente da UFMG, efeito que se verificou com maior expressão entre os professores mais experientes. Esse fato, certamente, dificulta a redução do número de alunos por turma. No entanto, acredita-se que a real compreensão do que representa - e sobretudo do que representará em um cenário de autonomia universitária efetiva - a manutenção de cursos com índices de evasão tão elevados, levará os Departamentos envolvidos a priorizar estratégias que venham a reduzir substancialmente a ocorrência desse evento.

\section{AGRADECIMENTOS}

Os autores agradecem à Pró-Reitoria de Graduação da UFMG, pelo apoio recebido, bem como aos colegas Professores Carlos
Alberto Lombardi Filgueiras, Jacques Schwartzman e Luiz Otávio Fagundes do Amaral, pelas críticas e sugestões.

\section{REFERÊNCIAS}

1. Paredes, A. S., A Evasão do Terceiro Grau em Curitiba, NUPES-USP, São Paulo, 1994.

2. Senapeschi, A. N.; Mendes, A. N.; Rdrigues, M. A.; Bocchi, N.; Silva, R. R.; Rocha-Filho, R. C.; Ciência e Cultura 1985, 37, 1397.

3. Silva, R. R.; Tunes, E.; Pachá, L. C. L.; Junqueira, R. M. P.; Quím. Nova 1995, 18, 210.

4. Elementos para um diagnóstico da Graduação da UNICAMP, Reitoria da UNICAMP, Campinas, 1992.

5. Ramos, M. N., Quadro de evasão na UFPE: metodologia, causas e ações, Pró-Reitoria para assuntos acadêmicos, Recife, 1995.

6. Estudo sobre evasão e retenção na UNICAMP (título presumido), UNICAMP, Campinas, 1995.

7. Dados sobre e evasão na UFMG, Pró-Reitoria de Graduação, Belo Horizonte, 1995.

8. Cipra, B.; Science 1991, 254, 370.

9. Lagowski, J. J., J. Chem. Educ. 1990, 67, 721. 